\title{
Miniature Transport Respirator Performance Evaluation for Ventilatory Support
}

\author{
Pimenta, FA*§; Leal, EB *; Fonseca, JWG*†; Valdigem, BP*; Andrade, \\ GC†; Biscegli, JF*; Andrade, AJP* \\ *Instituto Dante Pazzanese de Cardiologia, São Paulo, Brazil. § Universidade de São Paulo, \\ São Paulo, Brazil. † Universidade São Judas Tadeu, São Paulo, Brazil.
}

\begin{abstract}
In the face of the coronavirus pandemic (COVID-19), in hospital and emergency units, there is low availability of mechanical respirator for patients in need of this support, greatly improving the survival rate. In these situations, there is a need for simpler equipment, easy access, low cost, and fast manufacturing. In this study, a 3D prototype transport respirator was developed using as a model the Takaoka 600 Mini Respirator, national technology from the 1950s. The influence of adjustable parameters of the respirator was evaluated to understand it is functioning: maximum and minimum lung pressure; respirator intake pressure; respiratory rate; inspiratory and expiratory time according to the sensitivity of the mini respirator; and pressure and flow of $\mathrm{O}_{2}$ line intake. The increase in sensitivity led to an increase in maximum and minimum pulmonary pressure, decreased inspiratory and expiratory time, with margins of $1 / 1$, $1 / 2,1 / 3$ inspiratory/expiratory time ratio (I/E ratio). The intake flow of $\mathrm{O}_{2}$ varied proportionally with the pressure of air intake into the respirator, with its increase leading to an increase in respiratory rate, without major influences on lung pressure and the $\mathrm{I} / \mathrm{E}$ ratio. $\mathrm{The} \mathrm{O}_{2}$ line intake pressure without major influences on lung pressure, showing and I/E ratio $>1$ in values below 3.5 $\mathrm{kPa} \times 100$. In conclusion, it was possible to obtain a pulmonary ventilator-dependent only on positive $\mathrm{O}_{2}$ flow, compact and effective for patient transport, and in cases of emergencies with control of maximum pressure and respiratory rate offered to the patient. Among the parameters evaluated for this respirator, an line pressure of $\mathrm{O}_{2}$ from $3.5 \mathrm{kPa} \times 100$, sensitivity between 3 and 5 , a flow of 5 to $15 \mathrm{~L} / \mathrm{min}$ is recommended.
\end{abstract}

Keywords. Transport respirator, Ventilatory support, Takaoka 600, COVID-19.

Introduction. Mechanical ventilatory support is of great importance in the survival of patients admitted to emergency hospital and intensive care units (ICUs). In face of today's outbreak of the disease caused by the new coronavirus (COVID-19) in hospital and emergency units $(1,2)$, there is low availability of mechanical respirators for patients in need of this support (3). In numbers, confirmed by WHO, COVID-19 generated 7,805,148 cases, with 431,192 deaths in 216 countries (WHO, data from 14 July 2020, 21:00 GMT-3) (4), not counting a large number of underreported cases and uncertainties (5). It is estimated that approximately $5 \%$ of patients with COVID-19 end up requiring ventilatory support (3). 
Currently, the respirators available in ICUs are developed with large management protocols and work in different modalities, either for non-invasive or invasive type ventilation (1). However, in emergencies, there is a need for simpler equipment, of easy access, with low cost and fast manufacturing.

Based on this theme, a mechanical transport respirator was developed. The development was based on the Takaoka 600 Mini Respirator, a national pneumatic respirator developed in the 1950s by Dr. Kentaro Takaoka, an anesthesiologist (6). The differential of this equipment is in its dimensions (fitting in the palm of one hand), it does not depend on electrical energy, only on a line of oxygen $(6,7)$, which is very important in emergencies.

The cycling of this respirator occurs by pressure (controlled pressure, PC) with CMV ventilation mode (controlled mandatory ventilation), i.e., breathing is generated and controlled by the respirator (control of respiratory rate, inspiratory time, I/E ratio, maximum inspiratory pressure) $(7,8)$.

Due to the large scale and decentralized production of this respirator, the Dante Pazzanese Institute of Cardiology opted to work with 3D prototyping in its development. To yield, once the functionality of the prototype was proven, the designs to be printed in $3 \mathrm{D}$ resin or polymeric filament printers.

Materials and methods. 3D Printing. The Takaoka 600 mini respirator was reverse engineered, prototyping the parts in a 3D printer (CONNEX 350, Objet, Israel) with resins (FullCure720, Objet, Germany) as the main material and (FullCure705, Object, Germany) as the support material.

The mini respirator (Figure 1) requires only the oxygen line provided to the patient for its operation. In general, cycling is ensured by a magnetic valve driven by the internal pressure of the oxygen gas. The valve acts under two positions determining the inspiratory phase (air entering the lungs) and the expiratory phase (air leaving the lungs).

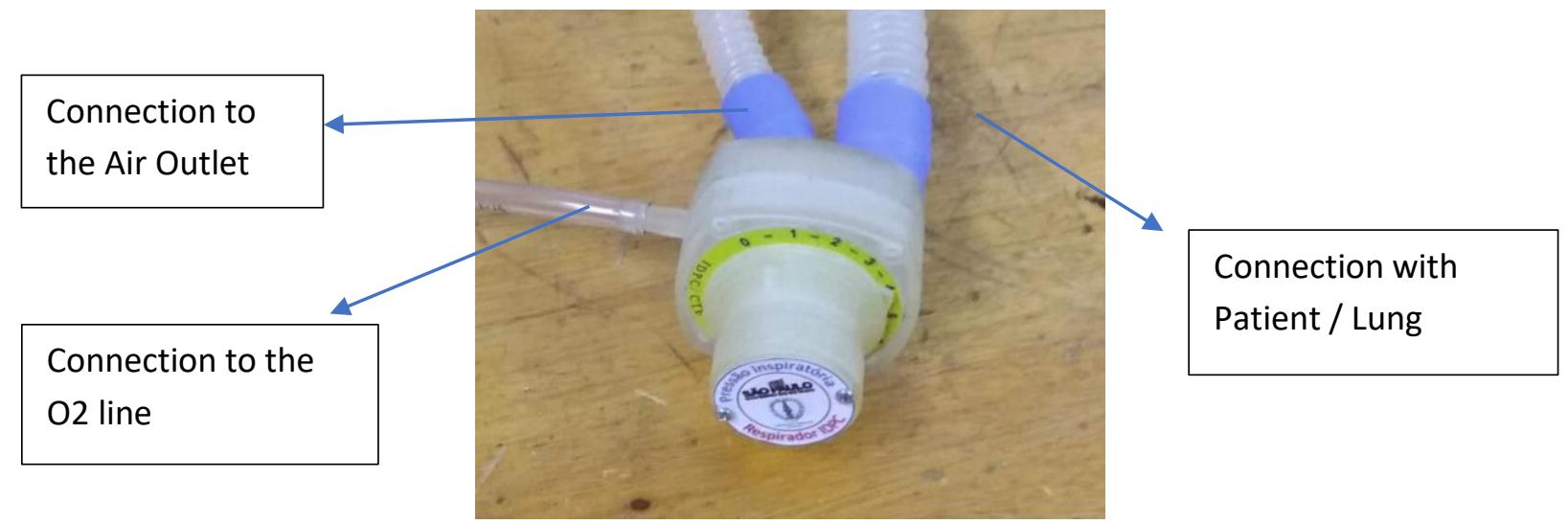

Figure 1. Reverse Engineering of the prototyped Takaoka 600 Mini-Respirator per 3D Printer. 
The sensitivity of the device is adjusted by the button at the top of the device, acting on the setting of the maximum inspiratory pressure.

Operational Evaluation. A test bench (Figure 2) was mounted with pressure sensors, a manometer, and a standard $\mathrm{O}_{2}$ line flow meter and expiratory phase regulator (FE Regulator). The collected data was recorded using an application developed in LabView® (National Instruments, Austin, USA) (Figure 3).

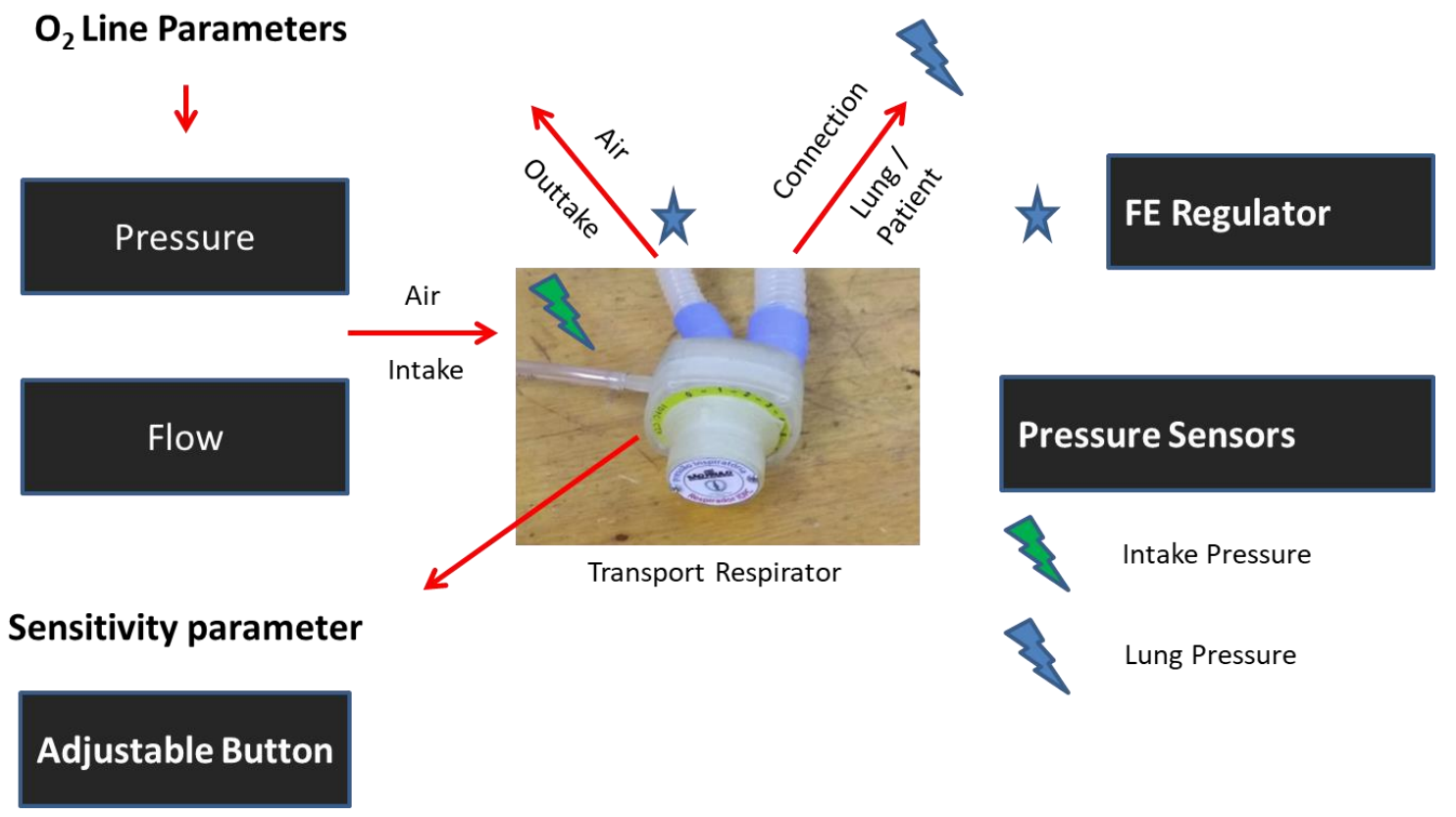

Figure 2. Test Bench Elements for the Performance Evaluation of the Mini-Respirator

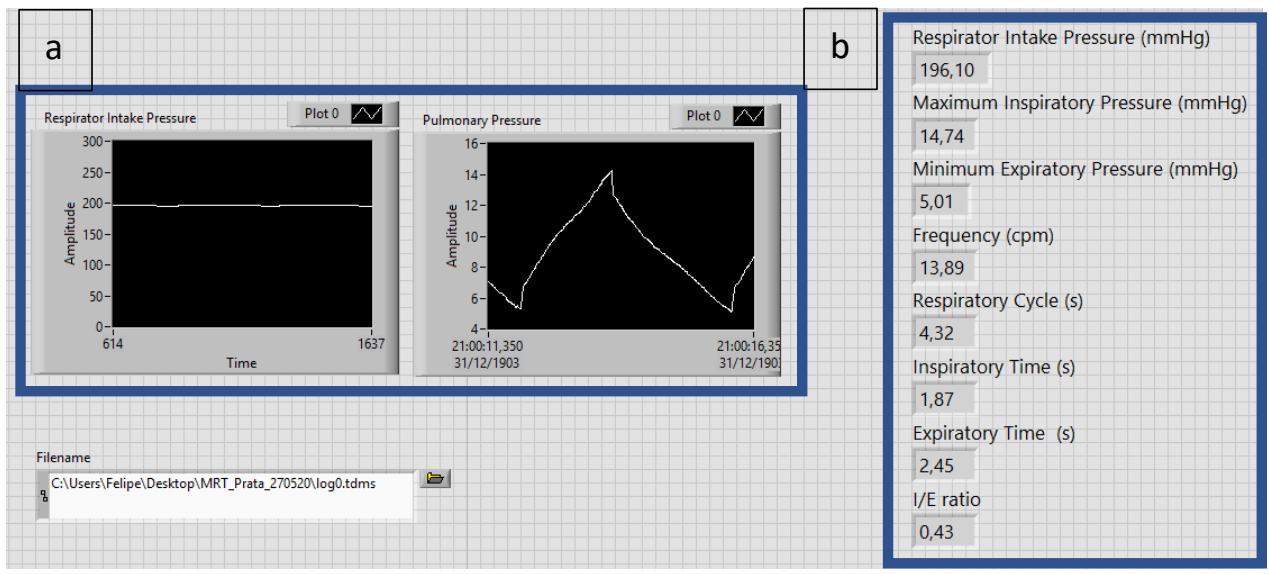

Figure 3. Image of the Mini-Respirator Functional Signal Capture System 
The data presented by the developed application demonstrate, the amplitude of the respirator intake pressure and pulmonary pressure for a respiratory cycle (period) for the corresponding time (Figure 3a), along with data on the respirator intake pressure, maximum inspiratory pressure, minimum expiratory pressure, frequency and respiratory cycle, inspiratory time and expiratory time, and the I/E ratio (inspiratory time / expiratory time) (Figure 3b).

The FE regulator (Figure 4) is represented by a resistance at the end of the air outlet from the lungs at expiration. In the evaluation test, this resistance was modeled as the adjustment of the height of the water column $\left(\mathrm{cmH}_{2} \mathrm{O}\right)$ inside a bottle. Due to infection problems related to the COVID-19 pandemic, a HEPA (High-Efficiency Particulate Air) filter was added to the air outlet of this regulator for particle retention.

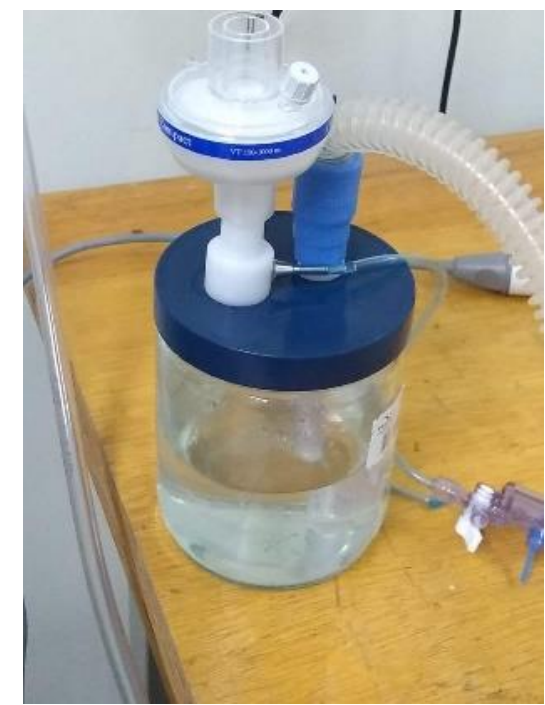

Figure 4. Expiratory Phase Regulator (FE Regulator).

The TAKAOKA 600 mini respirator has a maximum inspiratory pressure of 70 to $80 \mathrm{cmH}_{2} \mathrm{O}$, with frequency control performed by the $\mathrm{O}_{2}$ intake flow (between 0 and $15 \mathrm{l} / \mathrm{min}$ ). The influence of the adjustable parameters of the respirator was evaluated to understand its operation: sensitivity, flow, and $\mathrm{O}_{2}$ line intake pressure (control parameter used when the flow meter is not available (7).

Maximum and minimum pulmonary pressure, respiratory inlet pressure, respiratory rate, inspiratory and expiratory times were evaluated according to the sensitivity of the mini respirator, pressure, and $\mathrm{O}_{2}$ line intake flow.

The lung model used in the test was an expandable pouch-shaped reservoir representing the lung of a $1 \mathrm{~L}$ adult individual (190\#6006832, Siemens, Germany) (9). 
To evaluate the influence of sensitivity adjustment on the behavior of the respirator, a pressure of $5 \mathrm{kPa} \times 100$ was maintained on the $\mathrm{O}_{2}$ intake and a flow of $12 \mathrm{~L} / \mathrm{min}$, maintaining the EF regulator at $2 \mathrm{cmH}_{2} \mathrm{O}$, varying the sensitivity from 0 to 10 .

To evaluate the influence of the $\mathrm{O}_{2}$ intake flow on the behavior of the respirator the $\mathrm{O}_{2}$ intake was maintained at a pressure of $5 \mathrm{kPa} \times 100$, sensitivity at 3.5, $\mathrm{FE}$ regulator at $2 \mathrm{~cm}_{2} \mathrm{O}$, varying the flow from 5 to $15 \mathrm{~L} / \mathrm{min}$.

To evaluate the influence of the $\mathrm{O}_{2}$ inlet pressure, the flow rate of $12 \mathrm{~L} / \mathrm{min}$, sensitivity at 3.5, with an $\mathrm{FE}$ regulator at $2 \mathrm{~cm} \mathrm{H}_{2} \mathrm{O}$, varying the inlet pressure from 3 to $7 \mathrm{kPa} \times 100$, was maintained at the $\mathrm{O}_{2}$ intake.

Results. Influence of Respirator Sensitivity. There was no cycling of the respirator not valued 10 of the sensitivity scale, so this situation was removed from the analyses below. Maximum and minimum lung pressure increased with increased sensitivity (Figure 5a,b). For sensitivity values lower than 3, the minimum pressure was negative (Figure 5b). Sensitivity affects both inspiratory time $\left(\mathrm{T}_{\mathrm{insp}}\right)$ and expiratory time $\left(\mathrm{T}_{\mathrm{exp}}\right)$, inversely proportional in the sensitivity adjustment range between 0 and 8.5, with an atypical value of the curve at a sensitivity of 1.5, increasing again in sensitivity of 9 and 9.5 (Figure 5c,d). The inspiratory time/expiratory time $\left(\mathrm{R} \mathrm{I} / \mathrm{E}\right.$ ) ratio was inverted in the sensitivity from 0 to $1.5,8$ (small difference, $\mathrm{T}_{\text {insp }}=0.54$ and $\left.\mathrm{T}_{\mathrm{exp}}=0.57\right), 9$ and 9.5 (Figure 5e).
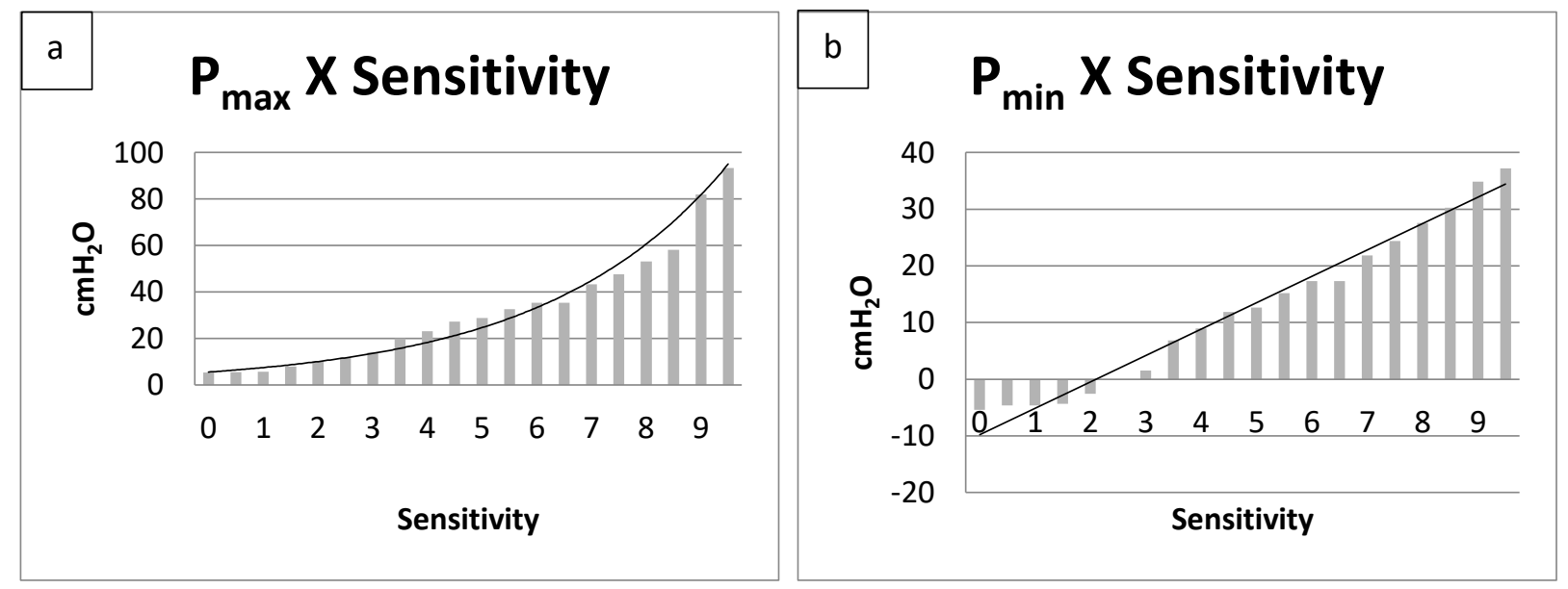

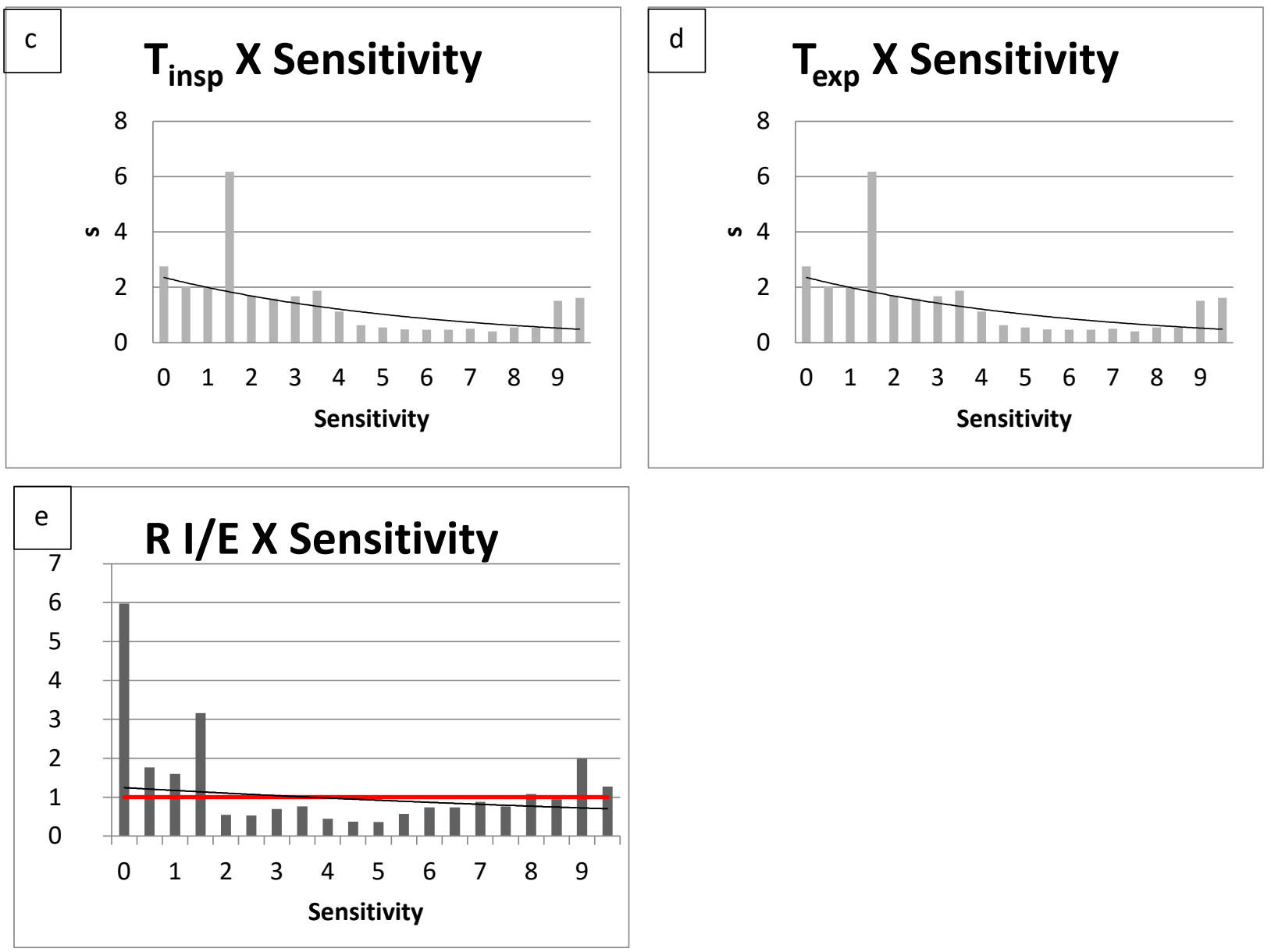

Figure 5. Influence of Respiratory Sensitivity on Maximum ( $\left.\mathrm{P}_{\max }\right)$ and Minimum $\left(\mathrm{P}_{\min }\right)$ Lung Pressures, Inspiratory ( $\left.\mathrm{T}_{\text {insp }}\right)$ and Expiratory $\left(\mathrm{T}_{\exp }\right)$ Times, and $\mathrm{T}_{\text {insp }} / \mathrm{T}_{\exp }$ Ratio $(\mathrm{R} \mathrm{I} / \mathrm{E})$

Influence of the $\mathrm{O}_{2}$ intake flow. The $\mathrm{O}_{2}$ inlet flow has a low influence on maximum and minimum pressure generated in the lung. For the flow ranging from 5 to $15 \mathrm{~L} / \mathrm{min}$, the maximum pressure varied from 19.43 to $19.69 \mathrm{cmH}_{2} \mathrm{O}$ and minimum pressure from 5.57 to $7.41 \mathrm{cmH}_{2} \mathrm{O}$ (Figure 6a,b). With the increase in flow, there is a proportional decrease in $\mathrm{T}_{\text {insp }}$ and $\mathrm{T}_{\exp }$ (Figure 6c,d), leading to an increased respiratory rate (Sumplentary Figure 1). The flow does not interfere in the $\mathrm{R} \mathrm{I/E}$ because all values are below 1 (Figure 6e). According to Figure 6f, the flow is proportional to the intake pressure of $\mathrm{O}_{2}$ on the respirator ( $\mathrm{P}_{\text {respirator intake). }}$ ). 

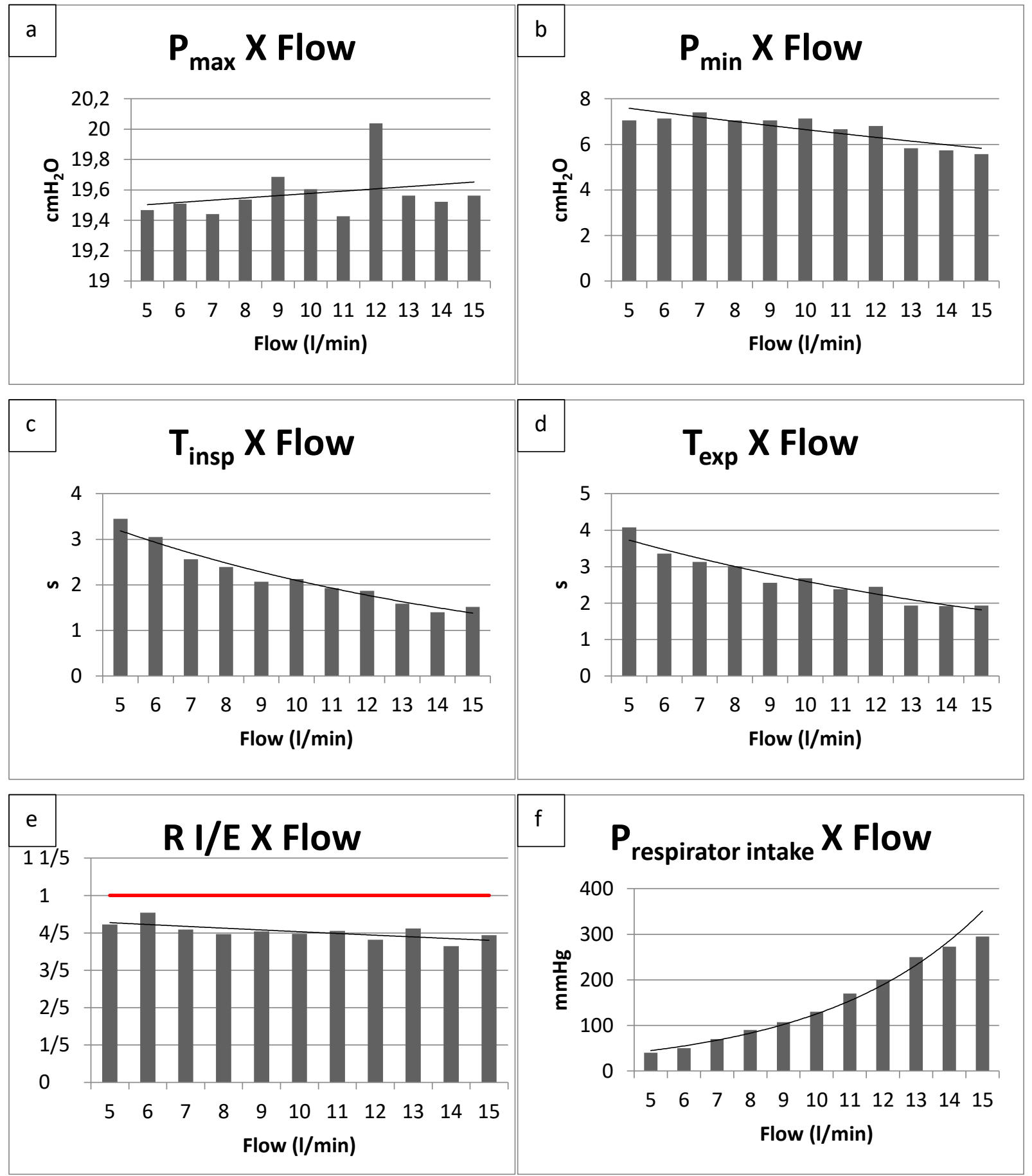

Figure 6. Influence of $\mathrm{O}_{2}$ Intake Flow on Maximum $\left(\mathrm{P}_{\max }\right)$ and Minimum $\left(\mathrm{P}_{\min }\right)$ Lung Pressures, Inspiratory $\left(\mathrm{T}_{\text {insp }}\right)$ and Expiratory $\left(\mathrm{T}_{\mathrm{exp}}\right)$ Times, $\mathrm{T}_{\text {insp }} / \mathrm{T}_{\exp }$ Ratio $(\mathrm{R} \mathrm{I} / \mathrm{E})$ and Respiratory Intake Pressure ( $\left.\mathrm{P}_{\text {respirator intake }}\right)$. 
Influence of the $\mathrm{O}_{2}$ line intake pressure. The $\mathrm{O}_{2}$ line intake pressure $\left(\mathrm{P}_{\text {oxygen line }}\right)$, as well as the flow (Figure $6 \mathbf{a , b}$ ) has little effect on the maximum and minimum pressure generated in the

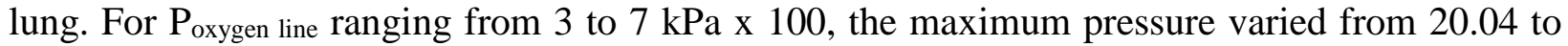
$19.33 \mathrm{cmH}_{2} \mathrm{O}$ and minimum pressure from 7.12 to $5.86 \mathrm{cmH}_{2} \mathrm{O}$ (Figure 7a,b). The Tinsp decreased slightly with the increase in intake pressure (Figure 7c). At the $3 \mathrm{kPa} \times 100$ inlet pressure, was lower than in other pressures, demonstrating an atypical value for the data. From $3.5 \mathrm{kPa} \times 100$ there is a reduction of $\mathrm{T}_{\text {exp }}$, stabilizing at pressures from 5.5 to $7 \mathrm{kPa} \times 100$ (Figure 7d). The R I/E was inverted in the $3 \mathrm{kPa} \times 100$ pressure, and in the others, the values were lower than 1 (Figure 7e). $\mathrm{P}_{\text {oxygen line }}$ is proportional to the inlet pressure on the respirator $\left(\mathrm{P}_{\text {respirator intake }}\right)$ (Figure 7f).
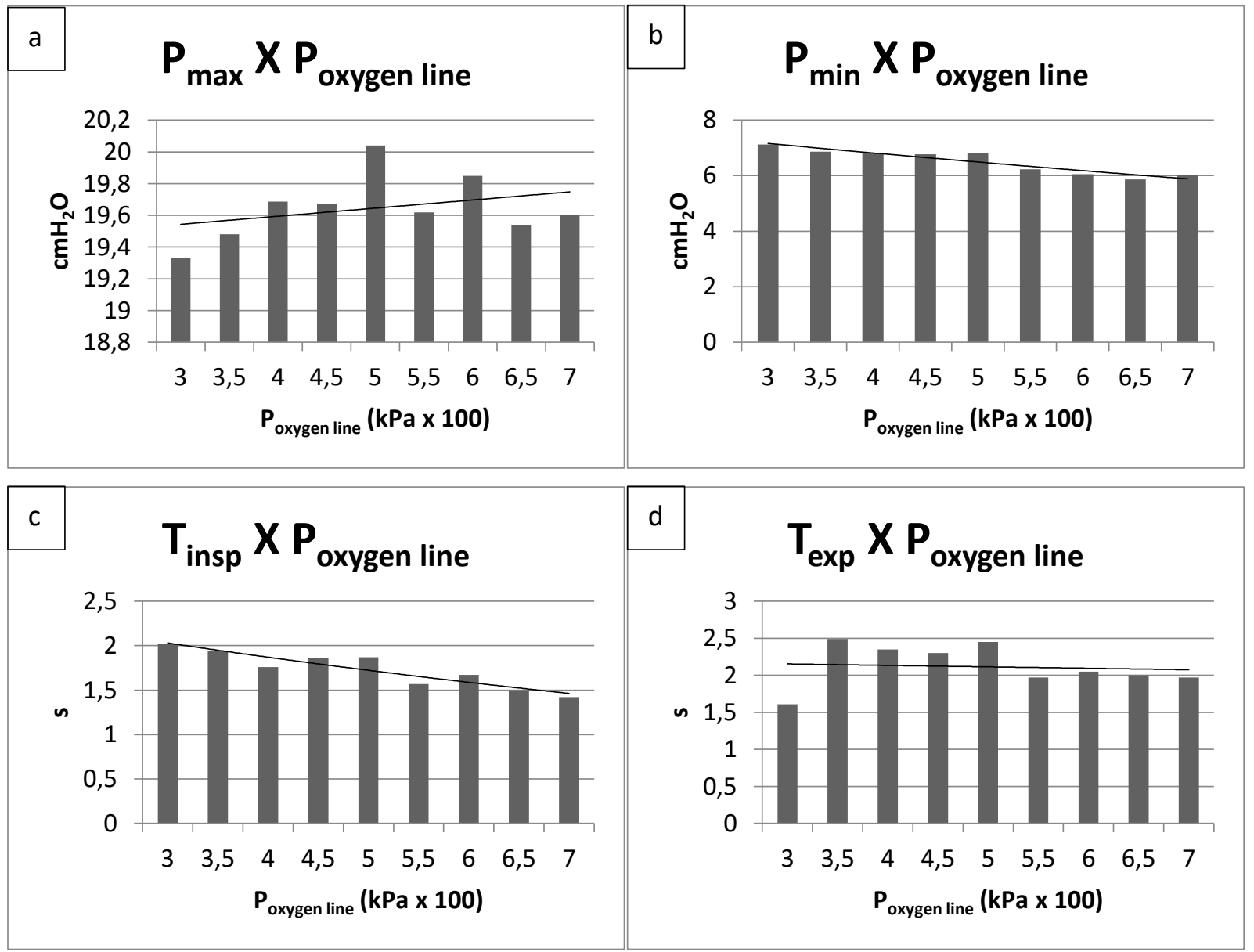


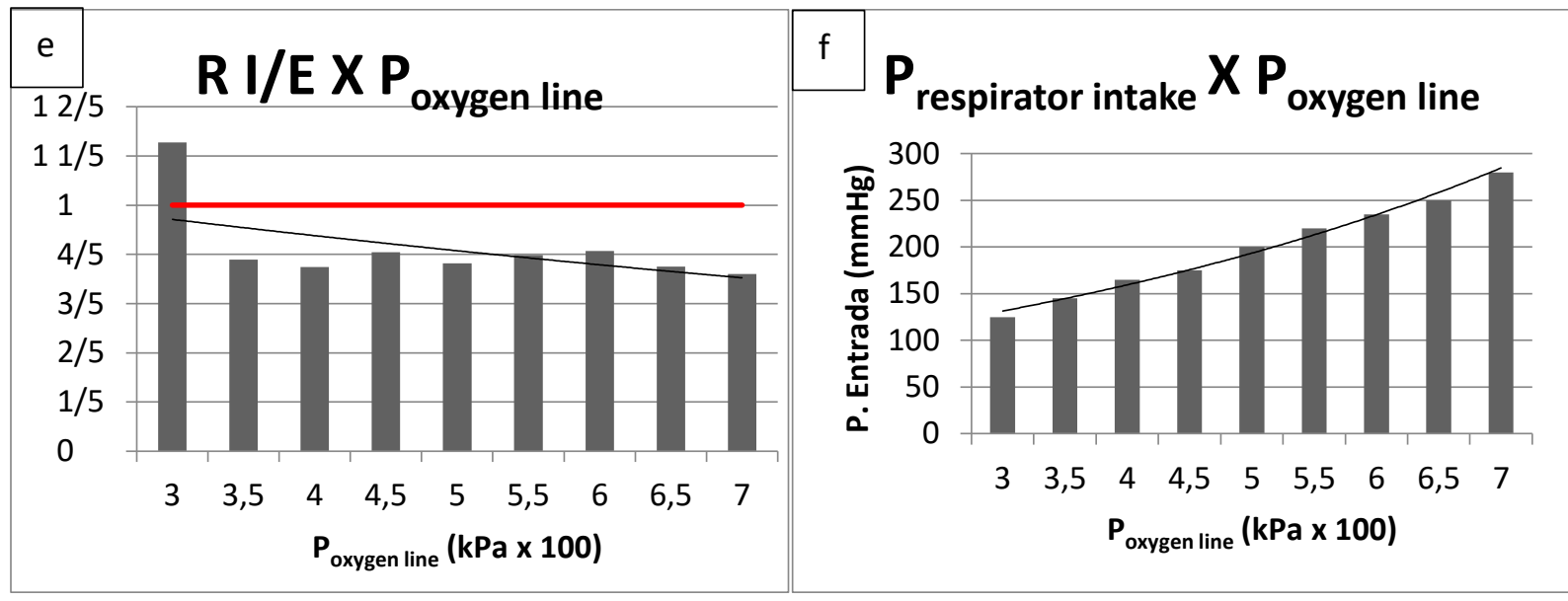

Figure 7. Influence of $\mathrm{O}_{2}$ Line Intake Pressure ( $\left.\mathrm{P}_{\text {oxygen line }}\right)$ on Maximum $\left(\mathrm{P}_{\max }\right)$ and Minimum $\left(\mathrm{P}_{\min }\right)$ Lung Pressures, Inspiratory $\left(\mathrm{T}_{\mathrm{insp}}\right)$ and Expiratory $\left(\mathrm{T}_{\mathrm{exp}}\right)$ Times, $\mathrm{T}_{\mathrm{insp}} / \mathrm{T}_{\mathrm{exp}}$ Ratio (R $\left.\mathrm{I} / \mathrm{E}\right)$ and Respiratory Intake Pressure ( $\left.\mathrm{P}_{\text {respirator intake }}\right)$.

Discussion. The positive end-expiratory pressure (PEEP) (represented here by Pmin) needs to be adjusted correctly for different pathologies. A minimum PEEP of $5 \mathrm{cmH}_{2} \mathrm{O}$ is generally recommended for an adult patient to avoid atelectasis. High PEEP values may be required in patients with COVID-19, values from 10 to $20 \mathrm{cmH}_{2} \mathrm{O}$, for alveolar recruitment purposes (8).

Here the minimum pulmonary pressure values were only lower than $5 \mathrm{cmH}_{2} \mathrm{O}$ for sensitivities adjusted from 0 to 3 , and up to 2.5 these values were negative (under the analyzed conditions) (Figure 5b). It is expected that PEEP can be altered by the FE (Expiratory Phase) regulator by the size of the water column. In the analyses, the water column remained constant at $2 \mathrm{~cm}$. The influence of the FE regulator on the functional state of the respirator should be evaluated.

Respiratory rate is an important parameter in mechanical ventilation, being controlled by the flow $(\mathrm{F})$ and by the intake pressure ( $\mathrm{P}_{\text {oxygen line }}$ ) $\mathrm{O}_{2}$ supplied to the developed respirator (8). According to RDC no. 386, dated May 15, 2020 (10), respiratory rate values should be within the range of 8 to 40 cycles per minute $(\mathrm{cpm})$. A frequency below $8 \mathrm{cpm}$ was demonstrated in two conditions: with $\mathrm{P}_{\text {oxygen line }}$ of $5 \mathrm{kPa} \times 100$, Flow of $12 \mathrm{~L} / \mathrm{min}$ and sensitivity of 1.5 , and the other with $\mathrm{P}_{\text {oxygen line }}$ of $5 \mathrm{kPa} \times 100$, Flow of $5 \mathrm{~L} / \mathrm{min}$ and sensitivity of 3.5 , presenting frequency values of 7.39 and $7.96 \mathrm{cpm}$, respectively. A frequency above $40 \mathrm{cpm}$ was observed in

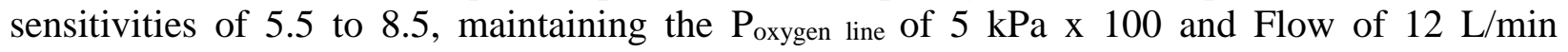
(Sumplentary Figure 1).

The $\mathrm{I} / \mathrm{E}$ ratio $(\mathrm{R} \mathrm{I} / \mathrm{E}$ ) in values of $1 / 2$ and $1 / 3$ are in general the most used, being $\mathrm{R} / \mathrm{E}>1$ unwanted in most procedures, associated with the development of dynamic hyperinflation (11). Values of R I/E > 1 were observed for sensitivities (Sens) adjusted between 0 and 1.5, 8 and 9 to 9.5 ( $\mathrm{P}_{\text {oxygen line }}-5 \mathrm{kPa} \times 100$, Flow - of $\left.12 \mathrm{~L} / \mathrm{min}\right)$ and for admission pressure of $3 \mathrm{kPa} \times 100$ 
(Flow of $12 \mathrm{~L} / \mathrm{min}$, Sens - 3.5) (Figure 5-e). The prototype generally demonstrated the operation with the R I/E at values close to 1 (Figure 5e; 6e; 7e), and in some cases with values at $1 / 2$ ( $\mathrm{P}_{\text {oxygen line }}-5 \mathrm{kPa} \times 100$, Flow $-12 \mathrm{~L} / \mathrm{min}$, Sens - 2 and 2.5) (Figure 5e) and 1/3 ( $\mathrm{P}_{\text {oxygen line }}-5$ $\mathrm{kPa} \times 100$, Flow $-12 \mathrm{~L} / \mathrm{min}$, Sens - 4 to 5) (Figure 5e). Thus, it can work in I/E ratios different from the 1/1 ratio presented by the Takaoka 600 (7), mini respirator, which was the model for making this respirator under study.

Maximum pressure can be controlled by varying the sensitivity of the respirator. Values greater than $50 \mathrm{cmH}_{2} \mathrm{O}$ may lead to the development of traumas such as pneumothorax and pneumomediastinum (12). These increased values were observed for sensitivity setting greater than or equal to 8 ( $\mathrm{P}_{\text {oxygen line }}-5 \mathrm{kPa}$ x 100, F -12 L/min) (Figure 5a). Reaching extremely high values in sensitivity of 9 and 9.5 ( $\mathrm{P}_{\text {oxygen line }}-5 \mathrm{kPa}$, Flow of $-12 \mathrm{~L} / \mathrm{min}$ ), 81.90, and 93.29 $\mathrm{cmH}_{2} \mathrm{O}$, respectively (Figure 5a). With the increase in the sensitivity of the respirator, there is an increase in both maximum and minimum pressure (Figure 5a,b).

Functional parameters are determined by the respirator inlet pressure, which is a variable dependent on the flow and $\mathrm{O}_{2}$ intake pressure. For better evidence, two conditions are shown: the first $\mathrm{P}_{\text {oxygen line }}=5 \mathrm{kPa} \times 100, \mathrm{~F}=11 \mathrm{~L} / \mathrm{min}$ and $\mathrm{Sens}=3.5$; and the second at $\mathrm{P}_{\text {oxygen line }}=4.5 \mathrm{kPa}$ $\mathrm{x} 100, \mathrm{~F}-12 \mathrm{~L} / \mathrm{min}$ and Sens - 3.5. Both conditions present values of pressures (Figure 7a,b), time (Figure 7c,d), and frequency similar (Sumplentary Figure 1). The common factor is also that respiratory intake pressure values are practically equal (170 and $175 \mathrm{mmHg}$, respectively) (Figure 7f).

Inlet pressure of $\mathrm{O}_{2}$ below $3.5 \mathrm{kPa} \times 100$ led to an $\mathrm{R} \mathrm{I} / \mathrm{E}>1$ (Figure 7e), thus being

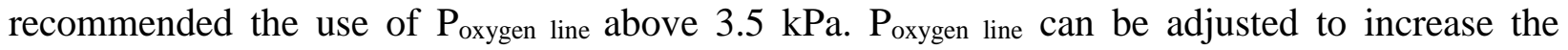
respiratory rate if the flowmeter is not available.

Conclusion. It was possible to obtain a pulmonary ventilator-dependent only on positive $\mathrm{O}_{2}$ flow, simple and effective for patient transport, and in emergencies. With maximum pressure control and respiratory rate offered to the patient. Among the parameters evaluated for this respirator, an $\mathrm{O}_{2}$ line intake pressure from $3.5 \mathrm{kPa}$ x 100, sensitivity between 3 and 5, a flow rate of 5 to $15 \mathrm{~L} / \mathrm{min}$ is recommended.

Future works: In vivo tests and clinical evaluation.

Acknowledgments. NIT Inova IDPC, FAPESP Projeto Temático 13/24434-0.

Disclosure. The authors report no conflicts of interest in this work.

\section{References.}

1. Kacmarek RM. The mechanical ventilator: Past, present, and future. Respir Care. 2011 Aug 1;56(8):1170-80.

2. Barbas CSV, Ísola AM, Farias AM de C, Cavalcanti AB, Gama AMC, Duarte ACM, et al. 
TAS Journal, vol. 2, n. 2, p. 131-143.

ISSN 2595-1521

JUNE 2020

f.pimenthas@gmail.com

Brazilian recommendations of mechanical ventilation 2013. Part 2. Rev Bras Ter Intensiva [Internet]. 2014 [cited 2020 Jun 15];26(3). Available from:

http://www.gnresearch.org/doi/10.5935/0103-507X.20140034

3. Wallace A. Coronavírus: como funcionam os respiradores e por que eles são chave na luta contra a covid-19 - BBC News Brasil [Internet]. BBC News Mundo. 2020 [cited 2020 Jun 15]. Available from: https://www.bbc.com/portuguese/internacional-52101349

4. WHO. Coronavirus disease 2019 [Internet]. 2020 [cited 2020 Jun 15]. Available from: https://www.who.int/emergencies/diseases/novel-coronavirus2019?gclid=EAIaIQobChMInLST0_eD6gIVSgeRCh1ypAJyEAAYASAAEgKtVvD_Bw $\mathrm{E}$

5. Jason Oke CH. Global Covid-19 Case Fatality Rates [Internet]. CEBM. 2020 [cited 2020 Jun 15]. Available from: https://www.cebm.net/covid-19/global-covid-19-case-fatalityrates/

6. KTK. Equipamentos e Aparelhos para Anestesias do Dr. Kentaro Takaoka [Internet]. [cited 2020 Jun 15]. Available from: http://www.ktk.ind.br/aparelhos-anestesiasmonitoracao-medica.html

7. MCAhospitalar. Ventilador pneumático - pressométrico MINI VENTILADOR 600 [Internet]. [cited 2020 Jun 15]. Available from:

https://www.mcahospitalar.com.br/ventilador-pneumatico-pressometrico-mini-ventilador600

8. Hess D, Kacmarek RM. Essentials of mechanical ventilation. 4th ed. United States: McGraw-Hill Education / Medical; 2018. 431 p.

9. Maquet. Siemens Adult 1 Liter Test Lung 190 \#6006832: Amazon.in: Industrial \& Scientific [Internet]. Amazon. 2019 [cited 2020 Jun 15]. Available from: https://www.amazon.in/Maquet-Siemens-Adult-Liter-6006832/dp/B007A1QC4U

10. ANVISA. RDC N ${ }^{\circ} 386$, DE 15 DE MAIO DE 2020 - DOU - Imprensa Nacional [Internet]. 2020 [cited 2020 Jun 3]. Available from: http://www.in.gov.br/web/dou//resolucao-rdc-n-386-de-15-de-maio-de-2020-258335933

11. Barbas CSV, Ísola AM, Farias AM de C, Cavalcanti AB, Gama AMC, Duarte ACM, et al. Brazilian recommendations of mechanical ventilation 2013. Part I. Rev Bras Ter Intensiva [Internet]. 2014 [cited 2020 Jun 15];26(2). Available from: http://www.gnresearch.org/doi/10.5935/0103-507X.20140017

12. Pádua AI, Martinez JAB. MODOS DE ASSISTÊNCIA VENTILATÓRIA. Med (Ribeirao Preto Online) [Internet]. 2001 Jun 30 [cited 2020 Jun 15];34(2):133. Available from: http://www.revistas.usp.br/rmrp/article/view/1230 
TAS Journal, vol. 2, n. 2, p. 131-143.

ISSN 2595-1521

JUNE 2020

f.pimenthas@gmail.com

\section{Supplementary Data}

Supplementary Figure 1. Respirator Respiratory Frequency (Freq) in the Pressure (Poxygen line) and $\mathrm{O} 2$ Intake Flow (F) and Respirator Sensitivity (Sens) parameters.

\begin{tabular}{|c|c|c|c|}
\hline $\mathbf{P}_{\text {oxygen line }}$ & $\mathbf{F}$ & Sens & Freq \\
\hline KPa X 100 & $L / \min$ & ---- & $\mathrm{cpm}$ \\
\hline 5 & 12 & 0 & 18.65 \\
\hline 5 & 12 & 0.5 & 19.05 \\
\hline 5 & 12 & 1 & 18.21 \\
\hline 5 & 12 & 1.5 & 7.39 \\
\hline 5 & 12 & 2 & 12.45 \\
\hline 5 & 12 & 2.5 & 13.03 \\
\hline 5 & 12 & 3 & 14.65 \\
\hline 5 & 12 & 3.5 & 13.89 \\
\hline 5 & 12 & 4 & 16.57 \\
\hline 5 & 12 & 4.5 & 25.81 \\
\hline 5 & 12 & 5 & 28.84 \\
\hline 5 & 12 & 5.5 & 45.70 \\
\hline 5 & 12 & 6 & 54.01 \\
\hline 5 & 12 & 6.5 & 54.01 \\
\hline 5 & 12 & 7 & 56,04 \\
\hline 5 & 12 & 7.5 & 62.97 \\
\hline 5 & 12 & 8 & 56.39 \\
\hline 5 & 12 & 8.5 & 54.28 \\
\hline 5 & 12 & 9 & 26.43 \\
\hline 5 & 12 & 9.5 & 20.86 \\
\hline 5 & 5 & 3.5 & 7.96 \\
\hline 5 & 6 & 3.5 & 9.37 \\
\hline 5 & 7 & 3.5 & 10.54 \\
\hline 5 & 8 & 3.5 & 11.11 \\
\hline 5 & 9 & 3.5 & 12.96 \\
\hline 5 & 10 & 3.5 & 12.48 \\
\hline 5 & 11 & 3.5 & 13.92 \\
\hline 5 & 13 & 3.5 & 17.01 \\
\hline 5 & 14 & 3.5 & 17.82 \\
\hline 5 & 15 & 3.5 & 17.36 \\
\hline
\end{tabular}


TAS Journal, vol. 2, n. 2, p. 131-143. ISSN 2595-1521

JUNE 2020

f.pimenthas@gmail.com

\begin{tabular}{|c|c|c|c|}
\hline 3 & 12 & 3.5 & 12.95 \\
\hline 3,5 & 12 & 3.5 & 13.53 \\
\hline 4 & 12 & 3.5 & 14.58 \\
\hline 4,5 & 12 & 3.5 & 14.41 \\
\hline 5,5 & 12 & 3.5 & 16.97 \\
\hline 6 & 12 & 3.5 & 16.13 \\
\hline 6,5 & 12 & 3.5 & 17.14 \\
\hline 7 & 12 & 3.5 & 17.72 \\
\hline
\end{tabular}

